\title{
Prevalence of geo-helminths eggs and cysts in soil samples of different primary and high schools of Quetta- Pakistan
}

\author{
Asiya Zahir, Zoha Tariq, Sehrish Lal Muhammad, Zubaida Kakar, \\ Umama Naseer and Nabeela Tariq* \\ Department of Zoloogy, Sardar Bahadur Khan Women's University, Quetta 87300- Pakistan \\ *Corresponding author's email: nabeela_trq@yahoo.com \\ Citation \\ Asiya Zahir, Zoha Tariq, Sehrish Lal Muhammad, Zubaida Kakar Umama Naseer and Nabeela Tariq. \\ Prevalence of geo-helminths eggs and cysts in soil samples of different primary and high schools of Quetta- \\ Pakistan. Pure and Applied Biology. Vol. 9, Issue 2, pp1341-1346. http://dx.doi.org/10.19045/bspab.2020.90140 \\ \begin{tabular}{llll}
\hline \hline Received: 06/11/2019 & Revised: 07/02/2020 & Accepted: 13/02/2020 & Online First: 24/02/2020 \\
\hline \hline
\end{tabular}
}

\section{Abstract}

Geohelminths are considered as most threatening to health. They can cause many diseases. The purpose of this study was to observe the soil samples which were collected from randomly selected private and government schools of Quetta city for the prevalence of geohelminths eggs and cysts. These samples were collected from washroom and playground of these schools and they were examined by using sucrose and zinc floatation techniques. Three genera of Nematodes (Whipworm, Ascaris and hookworms) were identified while cysts and oocysts of protozoans were not found. The contamination in the soil samples of different schools due to Ascaris lumbricoides was $86.3 \%$, Trichuris trichuria was $9.0 \%$ and Taenia sp $4.5 \%$. Percentage of Ascaris lumbricoide eggs were high as compared to those of Trichuria Trichuria and Taenia sp eggs percentage. Large number of Ascaris lumbricoide eggs prevalence was due to presence of inner shell of lipoprotein present in them. This layer makes them more resistant to harsh environment and also due to the fact that single female of Ascaris lumbricoide lays 200.000eggs/day. The contamination of Trichuria Trichuria eggs in soil sample of different schools was low due to the fact that their single female lays less number of eggs and they can easily be damaged by desiccation, Taenia $s p$ eggs were also low in quantity due to improved farming condition and livestock. To ensure effective environmental health, there is necessity of sanitary education, enforcement of basic rules of hygiene, and deworming of study area in general and in the schools in particular in order to prevent helminth infections.

Keywords: Cysts; Contamination; Geo helminths; Nematodes; Oocysts; Zinc-floatation technique

\section{Introduction}

Helminths are parasitic worms and are recognized as important public health problem [1]. Soil transmitted helminths (STHs) infect hundreds of millions of people in the world [2]. The intestinal parasites are threatening risk factor for both animals and humans [3]. The most threatening and common helminth infection of Ascaris lumbricoides which globally infect up to one third of the world's population and according to $\mathrm{CDC}$, it is responsible for10,000-20,000 deaths annually. Tropical, subtropical and rural areas of developed countries where there are poor hygiene and poor sanitation systems are the most common areas for infection. Children are particularly more vulnerable as compared to adults just because of behavior conducive to transmission of the parasite 
[4]. The most common and well known intestinal geohelminths are hookworms (Ancylostoma duodenale and Necator americanus), whipworm (Trichuris trichuria) and common round worm [5]. The estimation of the infection of these geohelminths intestinal parasites is approximately 1 billion, 770 million and 800 million respectively [6]. Soil Transmitted helminths are commonly found in areas with warm and moist climate where sanitation and hygiene system are very poor [7]. Ascaris eggs hatches at the temperature of 5 to $38^{\circ} \mathrm{C}$ from 8 to 37 days and Trichuris trichuria hatch at 5 to $38^{\circ} \mathrm{C}$ temperature from 20 to 100 days, while 2 to 14 days are required for incubation of hookworm eggs at $40^{\circ} \mathrm{C}$ or below to become infective larvae [8]. Geohelminth infections are spread through the ingestion of their ova and for a long period of time, they can survive outside the host or through larvae penetrating skin. Once inside the body, geohelminth hatch and undergo maturation stage in the tissues before enter in to the gut or intestine. Then they grow and undergo sexual reproduction stage for the production and development of eggs or larvae which are passed out from the feces in to the environment [9]. Due to vulnerability to nutritional deficiency in small children of aged below 12 and they usually play with soil so as a result they ingest the eggs or cysts of these geohelminths parasites [10]. Twenty schools of Quetta city were randomly selected for this study for the variable prevalence of soil contamination with different eggs of geohelminth parasites. For this study, there is need to collect the soil sample around washrooms and playgrounds so as to take preventive and prohibitive measures to avoid the impact of the disease. The purpose of present study was to determine the profile and prevalence of geohelminth eggs and cysts in soil samples of different primary and high schools of Quetta city.

\section{Materials and methods Study area}

Quetta is the capital of Balochistan, which is the largest province in Pakistan. Quetta valley is about $1650 \mathrm{~m}$ sea level and surrounded at it is by imprising hills on all slides. Quetta is sited at latitude $29^{\circ} 48^{\prime}$ to $30^{\circ} 25^{\prime}$ North and longitude $66^{\circ} 13$ to $67^{\circ} 17$ East having an area of about $2,653 \mathrm{~km} 2$. The city has great importance due to its geographical location. Quetta district has Uni-modal pattern of rainfall. This city accepts precipitation only from west disturbance in winter season summer monsoon is at very low rate. The climate of Quetta is dry with very cold $\left(15\right.$ to $\left.-7 c^{\circ}\right)$ in winter and relatively mild in summer season and windy conditions results removal of moisture contents from the upper surface of soil at high speed.

\section{Study design}

Twenty schools of Quetta city were randomly selected for this study. The selected schools were Telecom foundation school, New crescent grammar high school, Government boys Kasi school, Saryab mills government school, Hazarah Society boys high school, Haji Gabi government boys high school, Islamia boys high school, Dairy farm government girls school, Passban public high school, The city school, Sandeman boys high school, Hira public high school, BMC model high school, Railway high school, Shaldarah high school, Jinnah grammar school, The Smart school, The Elegance school, Mohsin public high school and EFA school (Fig. 1).

\section{Sample collection}

These twenty soil samples were collected from September to November month in 2018. Two sites of schools were selected for sample collection: one was from playground site and other was near the washroom. Soil samples were collected in small plastic bags by using a clean spoon. The plastic bags were labeled with the school name, sample site and the date. For parasitological analysis, these bags were then transported to laboratory.

\section{Survey method}

In laboratory each soil sample was sieved with the Laboratory Test Sieve (SER.NO.7130792) of 250 um to remove 
large particles. Then the soil samples were analyzed by zinc sulphate floatation technique for the examination of helminths eggs.

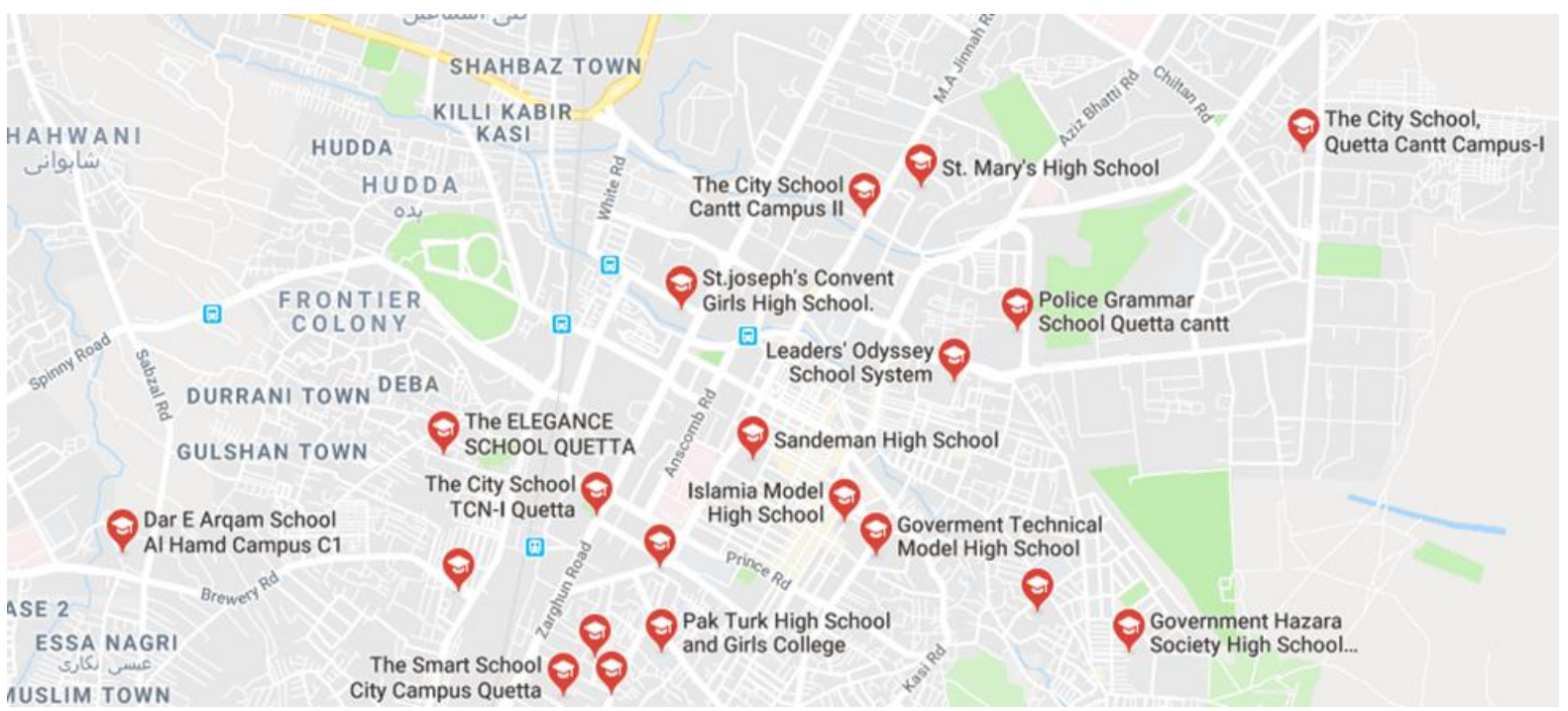

Figure 1. Map of Quetta city showing study area and sampling points. Source Google map satellite image

\section{Zinc sulphate floatation technique}

The zinc sulphate floatation technique was applied for the egg recovery from soil samples as described by Ayres and Mara [11]. 30 grams of zinc sulphate was mixed with $52.8 \mathrm{ml}$ of distilled water by the help of measuring cylinder. In this way the zinc sulphate floatation fluid with specific gravity of $1.3 \mathrm{~g} / \mathrm{ml}$ was prepared. Then 5 grams of sieved soil was weighted on Digital Measuring Balance. Mixed the soil with 10 $\mathrm{ml}$ of distilled water in falcon tube and centrifuged the tube at $1000 \mathrm{rpm}$ for 5 minutes. After 5 minutes the supernatant was disposed and the pellet was filled with $10 \mathrm{ml}$ of zinc sulphate floatation fluid. The mixture was shaken vigorously and centrifuged again at $2000 \mathrm{rpm}$ for 10 minutes. After centrifugation, cover slip was place on the tube in such a way that the mixture touches the cover slip. Then kept the tube in the test tube rack without any disturbance for 10 minutes. After 10 minutes removed the cover slip from falcon tube and placed it on clean slide with one drop of Lugol iodine solution. Placed another cover slip on the same falcon tube for 30 minutes. After 30 minutes removed the cover slip and placed it on another clean slide with one drop of Lugol iodine solution. Then, the two prepared slides were observed under a microscope (LEICA DM LS2).

\section{Results and discussion}

Among the 40 soil samples collected from different schools of Quetta city only 13 were positive to helminths eggs. Three types of helminths eggs were identified in soil samples collected from schools. Among these samples were contaminated with Ascaris eggs (Fig. 2), Trichuris (Whipworm) eggs (Fig. 3) and Taenia eggs (Fig. 4). Different plant fibers and miscellaneous items were also observed in soil samples. The Ascaris eggs were found most prevalent with highest percentage of 86\% while Trichuris and Taenia eggs were found with the 9.0 and $4.5 \%$ respectively (Table 1 \& Fig. 5).

From 20 different schools of Quetta, 40 soil samples were obtained and examined for helminths eggs. This study found that contamination of soil samples were due to 3 types of helminths eggs: Ascaris, Trichuris and Taenia. This study is similar to studies reported in Dschang, west Cameroon [12]. Soil transmitted Helminths in Dschange has revealed the presence of nematodes eggs namely, Ascaris and Trichuris. Other than 
this they also observed the presence of Hookworm, Cooperia and Capillaria eggs which were not found in soil samples of Quetta. Absence of Cooperia and Capillaria eggs in this study could be justified due to absence of animal husbandry in the city. A similar study conducted in west Cameron showed the similar result with maximum percentage of Ascaris followed by Trichuris. They found five genera of nematodes (Ascaris, Trichuris, Capillaria, Cooperia, and hookworms) in soil samples of ten primary schools [1].

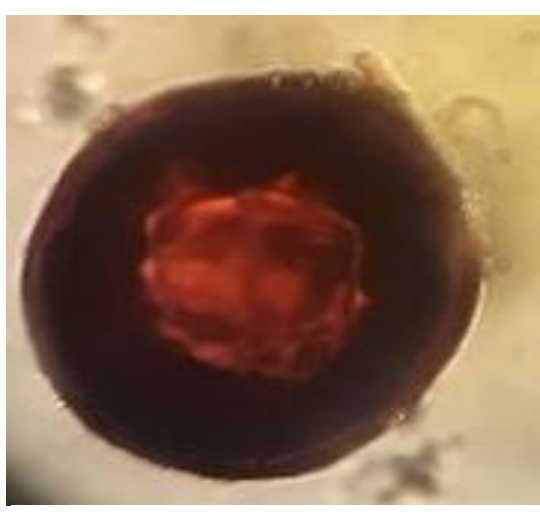

Figure 2. Ascaris egg

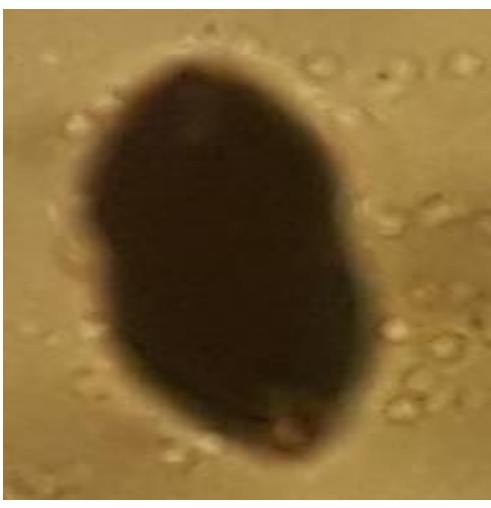

Figure 3. Trichuris egg

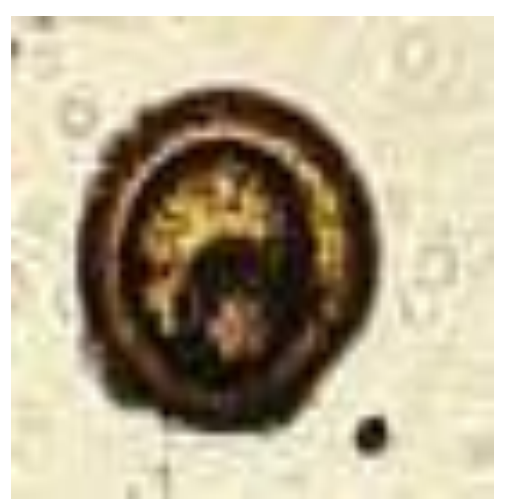

Figure 4. Taenia egg

Table 1. Frequency and percentage of helminths eggs found in soil samples per sampling sites

\begin{tabular}{|c|c|c|c|c|}
\hline Helminths & Playground & Washroom & Frequency & Percentage (\%) \\
\hline Ascaris & 8 & 11 & 19 & $86.3 \%$ \\
\hline Trichuris & 0 & 2 & 2 & $9.0 \%$ \\
\hline Taenia $s p$ & 1 & 0 & 1 & $4.5 \%$ \\
\hline Total & 9 & 13 & 22 & \\
\hline
\end{tabular}

-

(1)

Percantage of helminths eggs found in soil sample per sampling site

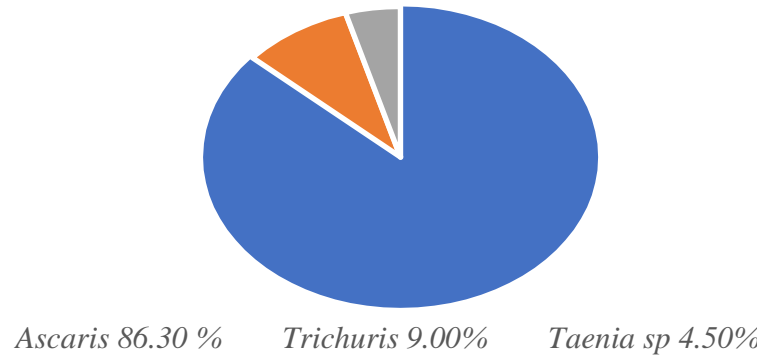

Figure 5. Pie chart of percentage of helminths eggs found in soil samples per sampling site

Ascaris eggs were found more commonly in the soil samples as compared to those of Trichuris and Taenia eggs. The high amount of Ascaris eggs in soil samples of this study can be justified by the fact that Ascaris eggs consist of an inner lipoprotein shell layer which makes them more resistant to harsh environment and air as compared to the eggs of other nematodes. The eggs of Ascaris are resistant to adverse environmental 
conditions and single female Ascaris lays 200,000 eggs/day so it might be another reason that mostly Ascaris eggs were identified $[13,14]$.

The low amount of soil contamination was observed with eggs of Trichuris. It might be due to fact that their single female lays less number of eggs and also due to desiccation their eggs were easily destroyed. Less number of Taenia eggs can be explained that there might be improvement in farming conditions.

A study was conducted on prevalence of gastro-intestinal parasites in $<15$ years old children in Muzaffarabad city in 2004. It reported prevalence of helminthes (Ascaris, Enterobius vermicularis, Trichuris trichiura, Hymenolepis nana and Taenia saginata) in stool samples of children [15]. Similar study was also conducted in district Mardan, KPK to investigate the prevalence of soil-transmitted helminth in school children. In this study Ascaris lumbricoides, Trichuris trichura and Ancylostoma duedenale were detected [16].

The contamination of soil found in the current study was lower than reported in other studies. This rate difference could be due to the factors such as socioeconomic and climatic while topographical characteristics and soil texture which varies within the countries also influences the distribution of helminths in the environment [14].

The low contamination rate of soil observed in this study could be due to improved living standards, health awareness, literacy rate and most importantly the schools of Quetta city were paved.

\section{Conclusion}

This study showed that the presence of helminths eggs in soil sample of different primary and high Schools of Quetta city. Three types of helminths eggs were observed in the soil samples along with different plant fibers. Ascaris eggs were more common as compared to Trichuris and Taenia eggs. The result obtained in this examination will spread the awareness among School going children to maintain their personal hygiene and wash their hands properly with hand sanitizer after using washroom.

\section{Authors' contributions}

Conceived and designed the experiments: $\mathrm{N}$ Tariq, Performed the experiments: A Zahir, Z Tariq, SL Muhammad, Z Kakar \& U Naseer, Analyzed the data: N Tariq, A Zahir, Z Tariq \& SL Muhammad, Contributed materials/ analysis/ tools: A Zahir, Z Tariq, SL Muhammad, Z Kakar \& $\mathrm{U}$ Naseer, Wrote the paper: $\mathrm{N}$ Tariq, A Zahir, Z Tariq \& SL Muhammad.

\section{Acknowledgment}

The authors would like to thank the administration of Schools of Quetta city to allow us to collect the soil samples.

\section{References}

1. Mahendra RS, Sein KT, Khairul AA \& Mustaffa BE (1997). Intestinal helminthiasis in relation to height and weight of early primary school children in northeastern peninsular Malaysia. Se Asian J Trop Med 28(2): 314-20.

2. Chan MS, Medley GF, Jamison D \& Bundy DA (1994). The Evaluation of Potential Global Morbidity Attributable to Intestinal Nematode Infections. Parasitol 109: 373-87.

3. Pullan RL, Smith JL, Jasrasaria R \& Brooker SJ (2014). Global numbers of infection and disease burden of soil transmitted helminth infections. Parasite Vectors 7: 37.

4. Sina H, Akre MA, Alia T \& Neil A (2012). GHEC (Global health education consortium), Soil Transmitted Helmminths.

5. Hotez PJ, Brooker S, Bethony JM, Bottazzi ME, Loukas A \& Xiao SH (2004). Current Concepts: Hookworm Infection. N Engl J Med 351: 799-807.

6. Amadi, E.C. and E.C. Uttah, (2010). Bionomics of Geohelminth Nematodes in Contaminated Foci in Parts of Abua Communities, Niger Delta, Nigeria (A). J Appl Sci Environ Manage 14: 6164

7. World Health Organization (2013). Soil-transmitted helminth infection. 
Fact Sheet No. 366.

8. Brooker S, Clement A \& Bundy D (2006). Global epidemiology, ecology and control of soil- transmitted helminth infections. Adv Parasitol 62: 221-61.

9. Stolzfus, RJ, Dneyfuss ML, Chwaya HM \& Albonico M (1997). Hookworm control as a strategy to prevent iron deficiency. Nutr Rev 55: 223-32.

10. OMS, Deworming for health and development (2005). Report of third global meeting of the partners for parasite control. World health organization (WHO), pp 5, Geneva.

11. Ayres \& Mara (1996). Analysis of waste water for use in agriculture; a Laboratory Manual of Parasitological and Bacteriological Techniques. $J$ Parasitol 81(1995): 404-405.

12. Vanessa RN, Blandine NT \& Josue W (2017). Profile of Geohelminth eggs, cysts and oocysts of Protozoans Contaminating the soils of Ten Primary Schools in Dschang, West Cameroon. $J$
Parasitol

Res.

doi.org/10.1155/2017/1534675

13. Soulsby EJL (1982). Helminths, arthropods and protozoa of domesticated animals, Baillere Tindal, London, 7th edition.

14. Appleton CC \& Gouws E (1996). The distribution of common intestinal nematodes along an altitudinal transect in KwaZulu-Natal, South Africa. Annals of Tropical Medicine and Parasitol 90(2): 181-188.

15. Chuadary ZH, Afzal M \& Malik MH (2004). Epidemiological Factors Affecting Prevalence of Intestinal Parasites in Children of Muzaffarabad District. Pak J Zool 36(4): 267-271.

16. Khan W, Khan J, Khan N, Iqbal R \& Atta Ullah et al. (2019). Soiltransmitted helminth infections in school children of three districts of Malakand region, Khyber Pakhtunkhwa, Pakistan. Pak J Pharm Sci 32(2 Suppl): 799-803. 